\title{
SIGNIFICADOS E SENTIDOS PARA PROFESSORAS DE CIÊNCIAS: ALGUMAS APROXIMAÇÕES.
}

\author{
Dianne Cassiano de Souza
}

A presente exposição traz algumas reflexões da dissertação de mestrado "A construção histórico social de gênero: significados sociais e sentidos para professoras de Ciências", desenvolvida no programa de pós-graduação em Educação para a Ciência da Faculdade de Ciências da Unesp, campus Bauru. A proposta é entender, ao longo da minha breve fala, como é a relação entre sentido e significado e como eu não posso analisar sentido sem analisar o significado. Acho que não posso me atrever a falar do materialismo histórico-dialético depois das palestras anteriores, nas quais ele foi brilhantemente apresentado, então me dedicarei a falar dos significados e sentidos na psicologia histórico-cultural.

Pensamos em concepção de homem ainda como aquele homem que produz, na sua atividade, a sua forma humana, ou seja, naquele homem que se humaniza através da sua atividade de trabalho, revelando em todas as suas expressões a sua historicidade social, as suas relações, o modo de produção e a ideologia. O trabalho, nesse sentido, é mediatizado desde a sua origem pelos elementos interdependentes, os homens e as relações com os outros homens, ou seja, a sociedade. No meu trabalho, discuti sobre como a atividade humana, o trabalho em si, tem um significado concreto importante no desenvolvimento não só da pesquisa, mas também do processo de humanização do homem e a sua importância, dado esse processo.

Entendendo o trabalho enquanto uma atividade que foi submetida, desde sua origem, às relações sociais, ela é a causa imediata que deu origem à consciência humana. Durante o processo de hominização, os animais entraram em atividade coletiva, passaram a se relacionar coletivamente e houve algumas mudanças na estrutura de suas atividades. A atividade deixou de coincidir com o seu motivo, ou seja, os homens tinham o objetivo de se alimentar, essa era a atividade deles, mas como eles estavam vivendo em uma comunidade eles não necessariamente "caçavam" diretamente sua comida. Então, a atividade dele deixou de coincidir com o seu motivo, com o motivo da atividade, ou seja, a gente vê um processo de parcelamento da atividade. Essa atividade antes era simples e se tornou complexa porque houve essa divisão entre os indivíduos que estavam ali vivendo em comunidade. Então, esse parcelamento da atividade fez com que tivesse que existir uma forma especificamente humana de reflexo da realidade, para que o ser humano pudesse compreender essa atividade ou a 
atividade dele submetido à essa divisão da atividade principal. Essa forma especificamente humana de reflexo da realidade é o que nós chamamos de consciência humana. O trabalho então modificou não só a estrutura geral da atividade, ele também teve influência no desenvolvimento dos instrumentos. Quando esses seres passam a utilizar os instrumentos, eles passam a ter consciência teleológica da ação do seu trabalho, ou seja, é necessário que ele realize generalizações das propriedades objetivas desses instrumentos para que ele possa compreender com qual objetivo ele vai utilizar esses instrumentos, por qual motivo.

Os instrumentos podem ser considerados os primeiros conhecimentos humanos passados para as próximas gerações. Com os instrumentos, com a realização do trabalho, com o surgimento da consciência humana, temos uma nova forma de reflexo consciente da realidade. Essa nova forma de reflexo consciente da realidade é o que nós chamamos de pensamento, é o pensamento humano. Ele consegue perceber as objetivas propriedades da realidade e consegue perceber, na verdade, os objetos que não são percebidos imediatamente. Essa percepção dos objetos não se dá só a partir das propriedades, mas também a partir dos significados desse objeto. Quando eu tenho a percepção desse significado do objeto, eu tenho uma percepção que é diferente dos demais animais, então, o reflexo consciente da realidade é qualitativamente diferente nos seres humanos. Ao longo da minha dissertação eu fiz uma discussão a respeito dessa diferenciação de como é a percepção para os animais e para os seres humanos, mas esse reflexo consciente diferente se dá através da linguagem, na percepção de determinado objeto.

A linguagem também teve origem na atividade produtiva. No início do processo de hominização, os antepassados animais dos homens passaram a viver em comunidade, fazer as divisões primitivas de trabalho e, nesse momento, houve a necessidade de comunicação. A linguagem surge nesse momento e tem ligação direta com a origem da atividade produtiva. Podemos caracterizar a linguagem como a forma e suporte da generalização da realidade, porque a partir da linguagem que eu não só vou me comunicar com os outros seres, mas eu vou expor os significados correspondentes às realidades, aos objetos, etc. Vigotski e Leontiev, que discutem sobre pensamento, linguagem, significado e sentido, foram dois dos principais autores que embasarem minha dissertação. Para esses autores, a compreensão da consciência se dá a partir da compreensão das relações entre pensamento e linguagem. A unidade entre pensamento e linguagem se dá no significado na palavra. E o que é esse significado da palavra? O significado da palavra, unidade indecomponível do pensamento e linguagem, é uma generalização, um conceito, é a própria palavra vista do seu interior. Toda a generalização se caracteriza pela ação do pensamento. Vemos aí a relação intrínseca entre pensamento e 
linguagem. Para Vigotski não há como você analisar pensamento e palavra, linguagem de forma separada.

Nesse sentido, a palavra é entendida como signo, sendo os signos instrumentos que permitem aos indivíduos entrarem em contato com o exterior. A palavra é o que chamamos de signo por excelência. Ela representa generalização e a forma de representação da realidade na consciência. Então, quando pensamos em significação, pensamos na palavra, na relação pensamento e linguagem, pensamos em generalização da realidade, ou seja, as significações, os significados, são produzidos a partir da generalização da experiência e das práticas sociais da humanidade e reproduzidos sócio historicamente.

E o sentido? Ao meu ver, o sentido é um pouco mais complicado, porque o sentido seria, de forma muito resumida, a soma dos fatos psicológicos que a palavra desperta no indivíduo. Ao tomar consciência das suas atividades, o indivíduo distingue essa relação como sua e o sentido consciente se dá nessa relação objetiva entre o indivíduo e aquilo que o faz agir e o resultado imediato para o qual a sua ação se direciona.

Dada essa breve explicação inicial sobre os conceitos de significado e sentido, qual é a relação de significados e sentidos com gênero e com o ensino de ciências? Eu utilizei significados e sentidos como uma forma de entendimento e compreensão dos significados e dos sentidos que as professoras, que foram entrevistadas, tinham e dos significados que eram transmitidos aos alunos. Eu gostaria muito, na verdade, que conseguíssemos investigar até mesmo os sentidos que são produzidos pelos alunos, a partir desses significados transmitidos pelos professores, mas foi uma dissertação de mestrado, então, não tive muito tempo.

$\mathrm{Na}$ minha dissertação, além de abordar o materialismo histórico-dialético, os significados e sentidos, eu também abordo gênero na construção da minha fundamentação teórico-metodológica. Eu tento trazer um pouco da questão de gênero também na perspectiva materialista histórico-dialética. Não consegui pensar em um trabalho que não tivesse uma fundamentação teórico-metodológica única do início ao fim, porque eu não entendo que dá para você pensar gênero em uma perspectiva liberal e trazer significados e sentidos na perspectiva materialista histórico-dialética. Então, nesse sentido, se pensamos nas relações entre homens e mulheres, entendemos que essas relações foram construídas, foram construções que são reproduzidas ou transformadas pelos indivíduos ao longo da história social, ou seja, o gênero é também resultado das relações de produção, das relações que se estabelecem na sociedade. De forma muito geral, gênero pode ser entendido como atributos e lugares, do feminino e do masculino, que são construídos sócio culturalmente, não como essência, mas com significados. 
$\mathrm{Na}$ minha pesquisa, utilizei uma autora de Araraquara muito conhecida, que é a Heleieth Saffioti, que trabalhou com gênero na perspectiva do materialismo histórico-dialético. Ela faz uma discussão sobre como a dominação capitalista de classe se efetivou produzindo e reproduzindo as diferenças que reforçam as desigualdades de classe, raça e gênero. E nesse contexto, Saffioti destaca a relação entre três sistemas vigentes de dominação e exploração, que se relacionam simbioticamente: o capitalismo, o racismo e o patriarcado.

Por fim, chegamos à discussão sobre o ensino de ciências. Por que eu, bióloga, fui me meter em uma discussão de gênero e sexualidade? Tem muitos autores que entendem que gênero e sexualidade não podem ser discutidos separadamente, então, se eu discuto gênero, eu tenho a obrigação de discutir sexualidade. Se eu discuto sexualidade, eu tenho a obrigação de discutir gênero. A sexualidade humana, assim como gênero, é também constituída a partir de determinações múltiplas, não apenas de fatores biológicos, mas também de fatores humanos, políticos, religiosos, sociais e históricos. Entendemos a construção de sexualidade, da mesma forma que entendemos a construção de gênero, mas claro, com as diferenças e as influências devido aos fatores biológicos. No ensino de ciências, os professores de ciências são os principais responsáveis, dentro da escola, pelas discussões de sexualidade e gênero, mas sabemos, a partir de uma longa investigação, que os professores ainda fazem o tratamento desses conceitos predominantemente a partir da dimensão biológica.

Nesse sentido, ao pensarmos a escola enquanto um espaço de socialização dos conhecimentos artísticos, científicos e filosóficos mais desenvolvidos, pensamos a educação sexual como um desses conhecimentos que devem ser transmitidos pela escola, enquanto saber sistematizado e elaborado. Tem um autor, o Marcio Magalhães da Silva, orientado da professora Lígia Martins, que fez uma pesquisa sobre a sexualidade na educação escolar e a pedagogia histórico-crítica. Eu quero destacar uma frase do artigo publicado por ele em 2015:

Para a pedagogia histórico-crítica a socialização de conhecimentos sobre o corpo humano, o aparelho sexual/reprodutivo, os métodos contraceptivos, as formas de contração das doenças, incluindo as DST, os modos de evitá-las, a concepção histórico-social do ser humano, englobando a construção social dos gêneros, etc., não pode depender da existência de um projeto de educação sexual na escola, pois esses conhecimentos são parte indispensável do conhecimento sobre a sociedade atual e o ser humano. Assim, todos os objetivos de formação da proposta de educação sexual do MEC devem ser contemplados pela proposta de socialização dos conhecimentos clássicos feita pela pedagogia histórico-crítica (SILVA, 2015, p. 84). 
Então, ele defende, na verdade, que a questão de sexualidade e gênero também faz parte dos conhecimentos clássicos que devem ser transmitidos pela escola. Nesse sentido, está justificada a importância dessa discussão.

Na minha dissertação eu também discuto sobre os parâmetros curriculares nacionais e sobre como a questão da sexualidade está inclusa no currículo e como tema transversal. Eu discuto também sobre a questão da escola, a escola enquanto espaço de produção e reprodução da heteronormatividade, a questão dos preconceitos e da discriminação de classe, raça, gênero e orientação sexual que fazem parte da configuração do espaço escolar. Discuto também sobre como a sequência sexo, gênero e sexualidade está presente no espaço escolar.

Finalizo comentando brevemente os procedimentos teórico-metodológicos. A minha referência teórico-metodológica ainda continua sendo o materialismo histórico dialético. Eu fiz entrevistas com três professores de ciências de uma cidade do interior de São Paulo e analisei as entrevistas utilizando os núcleos de significação pensados por Aguiar e Ozella, que fazem a investigação dos significados e sentidos na construção desses núcleos de significação.

Por fim, concluo dizendo que o cotidiano escolar está permeado por significados que expressam a dominação do gênero feminino pelo gênero masculino e reproduzem as relações de exploração e dominação. Então, a escola é uma reprodutora das relações de distinção de gênero, raça e classe, confirmando o que outros pesquisadores já demonstram. Não há uma percepção, nem dos professores de ciências e biologia, nem dos alunos, dos discursos de dominação que estão presentes no currículo de ciências, nos livros didáticos, etc. Nesse contexto, as professoras entrevistadas são também transmissoras dos significados sociais preconceituosos e normalizadores, que reforçam e contribuem para hierarquização e opressão das mulheres.

Então, os significados e sentidos que estão presentes nas aulas de ciências são marcados por essas relações desiguais entre sexo, opressão e preconceito e, principalmente, pela concepção biologicista e reducionista de gênero e sexualidade. Apesar da exposição breve e curta da minha pesquisa de mestrado, o objetivo era contar um pouco sobre como o materialismo histórico-dialético e a psicologia histórico-cultural estavam presentes nas análises sobre gênero e sexualidade.

\section{Bibliografia}

AGUIAR, W. M. J. A pesquisa em psicologia sóciohistórica: contribuições para o debate metodológico. In: BOCK, A. M. B.; GONÇALVES, M. G. M.; FURTADO, O. (org.). 
Psicologia sócio-histórica: uma perspectiva crítica em psicologia. São Paulo: Cortez, 2001. p. 129-140.

AGUIAR, W. M. J.; MACHADO, V. C. Psicologia sócio-histórica como fundamento para a compreensão das significações da atividade docente. Estudos de Psicologia, Campinas, v. 33, n. 2, p. 261-270, 2016.

AGUIAR, W. M. J.; OZELLA, S. Núcleos de Significação como instrumento para a apreensão da constituição dos sentidos. Psicologia Ciência e Profissão, Brasília, v. 26, n. 2, p. 222-245, 2006.

AGUIAR, W. M. J.; OZELLA, S. Apreensão dos sentidos: aprimorando a proposta dos núcleos de significação. Revista Brasileira de Estudos Pedagógicos, Brasília, v. 94, n. 236, p. 299-322, 2013.

AGUIAR, W. M. J.; SOARES, J. R.; MACHADO, V. C. Núcleos de significação: uma proposta histórico-dialética de apreensão das significações. Cadernos de Pesquisa, São Paulo, v. 45, n. 155, p. 56-75, 2015.

ARAÚJO, C. Marxismo, feminismo e o enfoque de gênero. Crítica Marxista, Campinas, v. 1, n. 11, p. 65-70, 2000.

ASBAHR, F. S. F. Sentido pessoal, significado social e atividade de estudo: uma revisão teórica. Psicologia Escolar e Educacional, Maringá, v. 18, n. 2, p. 265-272, 2014.

CHAVES, S. A. A hierarquia de gênero no fundamento teórico da disciplina de Ciências Naturais do Ensino Fundamental I. Educação em Revista, Marília, v. 15, n. 1, p. 37-90, 2014.

CISNE, M. Gênero, divisão sexual do trabalho e serviço social. 2. ed. São Paulo: Outras Expressões, 2015.

DUARTE, N. Formação do indivíduo, consciência e alienação: o ser humano na psicologia de A. N. Leontiev. Caderno CEDES, Campinas, v. 24, n. 62, p. 44-63, 2004.

DUARTE, N. A individualidade para si: contribuição a uma teoria histórico-crítica da formação do indivíduo. 3. ed. Campinas: Autores Associados, 2013.

FIGUEIREDO, V. A. A. Gênero, patriarcado, educação e os parâmetros curriculares nacionais. Caderno Espaço Feminino, Uberlândia, v. 21, n. 1, p. 37-53, 2009.

GÓES, M. C. R.; CRUZ, M. N. Sentido, significado e conceito: notas sobre as contribuições de Lev Vigotski. Pro-Posições, Campinas, v. 17, n. 2, p. 31-45, 2006.

GONÇALVES, R. O pioneirismo de A mulher na sociedade de classes. In: SAFFIOTI, H. I. B. A mulher na sociedade de classes: mito e realidade. 3. ed. São Paulo: Expressão Popular, 2013. p. 11-25.

JUNQUERIA, R. D. (org.). Diversidade sexual na educação: problematizações sobre a homofobia nas escolas. Brasília: Ministério da Educação, Secretaria de Educação Continuada, Alfabetização e Diversidade, UNESCO, 2009.

JUNQUERIA, R. D. (org.). Currículo heteronormativo e cotidiano escolar homofóbico.

Espaço do Currículo, Paraíba, v. 2, n. 2, p. 208-230, 2010. 
LEONTIEV, A. N. Actividade, consciencia e personalidade. Tradución: Librada Leyva Soler; Rosario Bilbo Crespo; Jorge C. Patrony Garcia. Ciudad de La Habana: Editorial Pueblo y Educación, 1983.

LEONTIEV, A. N. O desenvolvimento do psiquismo. Tradução: Rubens Eduardo Frias. 2. ed. São Paulo: Centauro, 2004.

MARIUZZO, T. Formação de professores em orientação sexual: a sexualidade que está sendo ensinada nas nossas escolas. 2003. 227 f. Dissertação (Mestrado em Educação para a Ciência) - Faculdade de Ciências, Universidade Estadual Paulista "Júlio de Mesquita Filho", Bauru, 2003.

MARTINS, L. M. As aparências enganam: divergências entre o materialismo histórico dialético e as abordagens qualitativas de pesquisa. In: REUNIÃO ANUAL DA ANPED, 29., 2006, Caxambu. Anais [...]. Rio de Janeiro: ANPED, 2006. p. 1-17.

MARTINS, L. M. Pedagogia histórico-crítica e psicologia histórico-cultural. In: MARSIGLIA, A. C. G. (org.). Pedagogia histórico-crítica: 30 anos. Campinas: Autores Associados, 2011. p. 43-58.

MARX, K. Contribuição à crítica da economia política. 2. ed. São Paulo: Expressão Popular, 2008. 285 p.

MARX, K. Cadernos de Paris \& manuscritos econômicos-filosóficos. São Paulo: Expressão Popular, 2015. 496 p.

MARX, K.; ENGLES, F. A ideologia alemã. São Paulo: Boitempo, 2007. 614 p.

MELO, A. S. A. F. Operação "Pente Fino": um levantamento das publicações sobre gênero, sexualidade e corpo nos ENPEC. In: ENCONTRO NACIONAL DE PESQUISA EM EDUCAÇÃO EM CIÊNCIAS, 11., Florianópolis, SC. Anais [...]. Santa Catarina: Abrapec, 2017. p. 1-9.

PASQUALINI, J. C.; MARTINS, L. M. Dialética singular-particular-universal: implicações do método materialista dialético para a psicologia. Psicologia \& Sociedade, Belo Horizonte, v. 27, n. 2, p. 362-371, 2015.

PEREIRA, Z. M. Gênero e sexualidade na pesquisa na área de ensino: análise da produção acadêmica. In: ENCONTRO NACIONAL DE DIDÁTICA E PRÁTICAS DE ENSINO, 16. 2012, Campinas. Anais [...]. São Paulo: Junqueira \& Marin Editores, 2012. p. 004168004179.

SAFFIOTI, H. I. B. O poder do macho. São Paulo: Moderna, 1987.

SAFFIOTI, H. I. B. Ontogênese e filogênese do gênero: ordem patriarcal de gênero e a violência masculina contra mulheres. Brasília: FLASCO-Brasil, 2009. (Série estudos/Ciências Sociais/). Disponível em:

http://www.flacso.org.br/portal/pdf/serie_estudos_ensaios/Heleieth_Saffioti.pdf. Acesso em: 22 ago. 2017.

SAFFIOTI, H. I. B. A mulher na sociedade de classes: mito e realidade. 3. ed. São Paulo: Expressão Popular, 2013.

SAVIANI, D. Pedagogia histórico-crítica: primeiras aproximações. 11. ed. Campinas: Autores Associados, 2011. 
SILVA, M. M. Pedagogia histórico-crítica e sexualidade na educação escolar: considerações a partir da análise do tema "Orientação sexual" nos parâmetros curriculares nacionais.

Germinal: Marxismo e Educação em Debate, Salvador, v. 7, n. 1, p. 78-88, 2015.

VIGOTSKI, L. S. A construção do pensamento e da linguagem. São Paulo: Martins Fontes, 2000 .

VIGOTSKI, L. S. A formação social da mente: o desenvolvimento dos processos psicológicos superiores. 6. ed. São Paulo: Martins Fontes, 2003. 